This is an Authors' Original Manuscript of an article whose final and definitive form, the Version of Record, will be published by Human Dimensions of Wildlife.

\title{
Community participation in ecotourism and its effect on local perceptions of snow leopard (Panthera uncia) conservation
}

\author{
Kate Vannelli*, Mark P. Hampton*, Tsewang Namgail ${ }^{\beta}$, and Simon A. Black*
}

\author{
Author Details: \\ Corresponding Author: Kate Vannelli \\ Phone: +1925348 5279 \\ Email: kvannelli@icloud.com \\ or kav3@kent.ac.uk \\ Mark P. Hampton: Email: m.hampton@kent.ac.uk \\ Tsewang Namgail: Email: tsewang.namgail@gmail.com \\ Simon A. Black: Email: s.black@kent.ac.uk \\ Affiliation of authors: \\ *University of Kent \\ Durrell Institute of Conservation and Ecology (DICE) \\ University of Kent \\ Canterbury \\ CT2 7NR \\ 及 Snow Leopard Conservancy - India Trust \\ Korban House, Changspa Sheldan \\ Leh, Ladakh-194101 \\ J\&K, India \\ Tel: 01982257953
}




\begin{abstract}
Local support and involvement is often essential for effective wildlife conservation. This study assessed the impact of local involvement in ecotourism schemes on perceptions of wildlife, promotion of conservation action, types of values that communities placed on wildlife, and contexts in which wildlife are considered to be most valuable. The study used qualitative semistructured interviews conducted in seven villages in Ladakh, India, which is an important region of snow leopard (Panthera uncia) habitat. Results indicated that in these communities, ecotourism-based interventions encourage more positive perceptions of wildlife species, in particular the snow leopard. Achieving change in community perceptions of wildlife is key when implementing ecotourism schemes to enable more effective conservation, as well as generating local awareness and value for wildlife toward problematic keystone species such as the snow leopard, which are frequently the focus of human-wildlife conflict.
\end{abstract}

Keywords: instrumental value, snow leopard, perceptions, ecotourism, human-wildlife conflict 


\section{Introduction}

Ecotourism can integrate wildlife conservation with human wellbeing (Stem, Lassoie, Lee, Deshler, \& Schelhas, 2003). Community-based ecotourism (CBET), which involves partial or full community ownership of an ecotourism enterprise (Wunder, 2000), seeks to make conservation and local livelihoods self-financing and sustainable as a long-term incentive for conservation (Krüger, 2005). Homestay programs are a common method, ideally capturing economic benefits locally to fight poverty (López-Guzmán, Sánchez-Cañizares, \& Pavon, 2011). Homestays bring tourists into regions that need diversified income, integrate tourists into local cultural norms (Namgail, Majumder, \& Dadul, 2016), and offer a degree of control for homeowners, which would all be lost if locals were employed in a large-scale lodge or hotel (Hampton, 2013). Homestay schemes that promote nature can give wildlife monetary value and encourage community stewardship of the environment (Namgail et al., 2016). However, critics of homestays highlight issues such as variable quality (e.g., village accessibility, training, management, investment), unequal distribution of benefits within communities, and income fluctuations due to seasonal tourism (Namgail et al., 2016).

The Snow Leopard Conservancy - India Trust (SLC-IT) operates the Himalayan Homestays Program (HHP), launched in 2002 by the Snow Leopard Conservancy (SLC), independently. Approximately 500 snow leopards (Panthera uncia) reside in India and have the highest level of protection under the Indian Wildlife Protection Act of 1972 (Bhatnagar et al., 2016). The HHP operates in several valleys in the Leh district of Ladakh, in the northern state of Jammu and Kashmir, where the main threat to the snow leopard is retaliatory killing by farmers (SLC-IT, 2017). Snow leopards can kill many livestock in a pen in one night, causing major financial loss for communities. Retaliatory killing of leopards is more likely if alternative 
incentives are absent, so programs aim to mitigate loss and foster human coexistence with snow leopards (Namgail et al., 2016).

The HHP provides benefits for local people including increased earnings from wildlife tourism and offsetting financial losses from livestock predation. The HHP also claims to change local attitudes toward these predators away from viewing them as pests, and increasing their value to the community (SLC-IT, 2017). Tourism-based conservation interventions such as the HHP must address how wildlife can become valuable to local people given that the support and involvement of people living alongside wildlife is essential (Agrawal \& Redford, 2006; Salafsky et al., 2001). An instrumental value for local wildlife could influence behaviors that most likely support conservation efforts without external compensation, resulting in effective and longlasting change (Berkes, 2004; Spiteri \& Nepal, 2008; Waylen, Fischer, McGowan, Thurgood, \& Milner-Gulland, 2015).

This paper explores three types of values: intrinsic, instrumental, and economic. Intrinsic value involves valuing nature irrespective of its use to humans. Instrumental value is derived from responses that nature produces in humans, including aesthetic, spiritual, and ecological values (Justus, Colyvan, Regan, \& Maguire, 2008). Economic value involves valuation dependent on money and market transactions. The indicators of socio-economic success for the HHP are measured by changes in local values and attitudes toward wildlife and tourists in conjunction with the program (SLC-IT, 2017). This study's objectives are to: (a) assess whether local involvement in ecotourism alters perceptions of wildlife and promotes conservation action; (b) identify how ecotourism brings about these changes, considering both direct and indirect pathways of influence; and (c) explore the values placed on wildlife by communities and the contexts in which wildlife are considered most valuable. The hypothesis is that the presence of 
the HHP increases positive perceptions of snow leopard conservation and increases the overall value of wildlife, which are both crucial in designing effective ecotourism for species such as snow leopard that are frequently involved in human-wildlife conflict (HWC).

\section{Methods}

The Ladakh region of northern India, which has several HHP villages, was the study site. Tourism in Ladakh accounts for 50\% of the gross regional product, but only $4 \%$ of employment (Loram, 2004). Most tourism in Ladakh is high volume, low value (Rajashekariah \& Chandan, 2013). A decrease in Ladakh's traditional livelihoods has increased interest in nature-based tourism due to the area's beautiful landscape and charismatic wildlife (e.g., snow leopards).

This study used qualitative semi-structured interviews, which are more flexible than questionnaires, better at contextualizing perspectives, and provide a deeper understanding of issues emerging during a study (Rust et al., 2017). A purposive sample was generated through snowball sampling covering five stakeholder types defined by the presence of the HHP in their

locality, degree of establishment of the HHP (long-term or short-term), and personal involvement in the HHP. Villages had varying exposure to conservation, ranging from none to more than 10 years of various interventions (e.g., HHP, handicrafts). The risk of inaccuracies in exploring local perspectives was minimized by using focused interviews, which allowed triangulation of findings from a relatively large sample (for qualitative research) of respondents. Interviews followed predetermined, open questions (to avoid ambiguous, unclear, or leading questions; Newing, Eagle, Puri, \& Watson, 2011) with flexibility to explore new topics as they arose. This approach suits local conversational culture.

Respondents $(n=49)$ were from four villages in the western Sham Valley and three villages in the eastern Rong Valley. Interviews were conducted in May 2017 by a translator 
using the local language (Ladakhi) covering questions specific to whether respondents were HHP participants $(n=19)$ or non-participants. Interviews lasted between 15 and 60 minutes.

Interviews were transcribed and annotated with themes and subthemes later identified by manual axial coding using NVivo qualitative analysis software.

\section{Results and Discussion}

The results are presented based on the major themes from the NVivo coding and supported by illustrative quotes in Table 1. Qualitative data represent the people affected directly or indirectly by conservation interventions, as well as communities with no interventions. About half of respondents had multiple income sources (e.g., subsistence agriculture, livestock, family members in military jobs, handicrafts, tourism) with the majority of the HHP participants at least partly dependent on income from tourism. The majority of respondents with one source of income ( $n=22)$ depended on subsistence agriculture and only two depended solely on the HHP.

Insert Table 1 about here

\section{Tourism Benefits to Communities}

Community benefits from tourism, economic or otherwise, is central to effective CBET (Khan, 1997; Liu, 2003). Results indicated that people involved directly in the HHP were perceived as receiving more benefits (mainly economic) than those who were not, although some others in the community perceived that there were advantages for all. Most respondents felt positive overall about increasing tourism in the area, and the associated economic benefits, learning benefits, and capacity building (Table 1).

In many of the communities, tourism was perceived to have improved daily life, but concerns were expressed over tourism's environmental impacts, specifically litter and pollution. However, some respondents stated that tourism had increased their awareness of the importance 
of keeping their village clean (Table 1). Some also stated that a cleaner environment would bring more tourists. Respondents noted that the SLC-IT had implemented infrastructure for managing litter in homestay villages and all respondents involved saw this as a benefit. Most respondents believed that tourism is increasing, predominantly driven by attraction to Ladakh's wildlife.

\section{Homestays and Perceptions of Wildlife}

Wildlife and tourism are closely linked in Ladakh, so it is useful to understand the relationship between participation in the HHP and perceptions of wildlife. Alongside known benefits from the HHP for local people, effects on wildlife need to be explored to understand the HHP relevance as a conservation intervention. Results showed many non-HHP participants not seeing benefits in wildlife, whereas the HHP participants felt greater responsibility for wildlife. Appreciation for snow leopards was higher in communities with the HHP, even among non-HHP participants (Table 1).

The HPP appears to have had a positive effect on local perceptions of wildlife, as shown in frequent discussions of the instrumental value of wildlife and specifically snow leopards in reference to their beauty (Table 1). When pride and value were discussed, many respondents mentioned happiness in seeing wildlife in groups, perhaps resonating with family bonds in their own culture. Some respondents expressed the importance of protecting wildlife for future generations, implying personal responsibility for conservation. One individual who discussed global warming emphasized that the snow leopard was exempt from this threat, suggesting a lack

of community awareness of risks to the species. Although current SLC-IT workshops for the HHP communities present the threats to the snow leopard and its ecological value, further development of communities' understanding may prompt further behavioral changes, and increase the impact of conservation efforts. 


\section{Value of Wildlife in Relation to Tourism}

To assess the value of wildlife based on tourism alone, respondents were asked how wildlife's value would change if tourism ceased in future. Of the 15 short-term homestay participants who claimed that local wildlife had value (economic and instrumental), all except one said wildlife would keep its value (Table 1). Of the seven long-term homestay participants who claimed wildlife had value, three said it might lose value if tourism stopped (Table 1).

\section{Temporal Changes}

Respondent perceptions of the past, present, and future were sought to assess changes over time and to project future conservation scenarios. HWC was perceived as decreasing, coinciding with establishment of the HHP. Some people spoke of a reduction in livestock in communities overall, and some spoke of changes in livestock management techniques guided by conservation NGOs (Table 1). Most respondents who lived in established homestay communities showed a greater appreciation for tourism and wildlife compared with those in communities with no interventions. Most respondents also expressed a desire for increased tourism in the future, as well as believing that wildlife was increasing (Table 1). This projection from past to future illustrates a changing community, transitioning from reliance on livestock farming to more varied income sources. This concurs with observations in the literature regarding Ladakh's socioeconomic situation (Bhatia, Redpath, Suryawanshi, \& Mishra, 2017).

Results showed that in communities without conservation interventions (homestays or other), there was generally a neutral or negative perception of wildlife, particularly the snow leopard, which was mainly due to HWC (Table 1). Many non-HHP respondents expressed frustration regarding the snow leopard taking livestock, and said their feelings about the snow leopard would be more positive if the species did not kill livestock. Attitudes toward wildlife 
were also mainly negative due to lack of benefits from tourism and HWC, implying that there is potential for change with implementation of the HHP and mitigation of HWC in the communities.

In communities that experienced a recent (3-7 years) inception of the HHP, several respondents said that outside interest in wildlife has changed their perception of wildlife, shifting them from ignorance to enjoyment (Table 1). People in these communities expressed an instrumental value in wildlife more frequently than those in communities without interventions (Table 1). Direct participants in the program expressed value in wildlife more often than those who were not. The majority of respondents in these communities were mainly dependent on subsistence agriculture, with additional income from tourism. The results imply that the HHP in the short-term has potential to instill instrumental value for wildlife without generating economic dependence on this wildlife. This is valuable in regions where the tourism market is unstable.

In communities that had long-term (10 or more years) HHP, results showed that wildlife had high value (both economic and instrumental) within the community for homestay and nonhomestay participants. In these communities, income from wildlife-related tourism was higher than in other communities, and it was apparent from researcher observations that investment in tourism infrastructure was relatively high. In one village, several privately-owned guesthouses were being constructed in addition to the homestays due to the increasing volume of visitors during tourist season. The respondents whose income relied entirely on homestays exclusively resided in these villages. Results indicated that as people become more exclusively dependent on wildlife tourism-based income, wildlife decreases in instrumental and intrinsic values, becoming increasingly commodified. If tourism development continues in this way in future, it could put additional pressure on the local communities that are dependent on fluctuating visitor numbers and on snow leopard presence to support their livelihoods. 
Prior to the HHP and other interventions, livestock depredation was the biggest barrier to snow leopard conservation. The HHP's benefits have promoted a positive attitude among participants toward snow leopard conservation. SLC-IT is taking this opportunity through a presence in the community and its own workshops to convey the instrumental value of snow leopards in keeping the mountain ecosystem intact. Although the possibility of people reverting to retaliation in the absence of tourism remains, SLC-IT is encouraging locals to conserve the snow leopards for their intrinsic and instrumental values.

There is much debate on the effectiveness of intrinsic, instrumental, and economic valuation of wildlife. Vucetich, Bruskotter, and Nelson (2015) argued that intrinsic value is central to conservation decision-making, whereas Justus et al. (2008) argued that it should not and suggested that instrumental valuation provides a stronger ethical basis. Chan et al. (2016) argued for use of a third category, relational values, which encompass both intrinsic and instrumental values within the frames of both individual and humans collectively. Although wildlife's economic value is an important motivator for conservation, findings here provide partial support for Chan et al. (2016) that instrumental value has stronger staying power and inspires longer-lasting conservation actions. If an ecotourism initiative focuses purely on economic value, this provides an unreliable basis for behavioral change since tourism-based markets can fluctuate and are unpredictable. Although intrinsic valuation of wildlife is appealing, the HHP's ability to inspire this in participants appears limited. This study suggests that the HHP and associated SLC-IT workshops have the potential to inspire instrumental and economic values in wildlife, with instrumental value reported consistently by respondents even if no income arises from tourists. This could be considered a counterbalance to pure commodification of wildlife fostered by exclusive tourism income. 


\section{Behavior Influences}

Results from this study suggested that perceived value is just one factor influencing behavioral change, since it interacts with attitudes, social norms, and perceived behavioral control, as reflected in the Theory of Planned Behavior (Ajzen, 1991) related to communities' responses to snow leopards (Figure 1).

\section{Insert Figure 1 about here}

Six respondents stated that the main reason they protect wildlife is because it attracts tourists, which is an intention and not necessarily a behavior. For the most part, homestay participants have greater levels of conservation awareness (i.e., 'wildlife related knowledge or observations'), so if influenced by additional factors, they are more likely to exhibit supportive behavior, especially regarding responses to livestock loss. Wildlife seems to hold the greatest instrumental value for local people when their income is not solely dependent on ecotourism. This means a need to balance wildlife tourism income with other income sources to shift the value of wildlife merely as a commodity toward intrinsic or instrumental value. Measures should be taken to move local perceptions of the value of wildlife beyond economic benefits toward instrumental values to foster longer lasting change that is less vulnerable to market fluctuations (Table 2).

Insert Table 2 about here

\section{Conclusion}

In the surveyed communities in Ladakh, ecotourism-based interventions are changing perceptions of wildlife, particularly for snow leopards, which historically had a poor reputation. A reduction in livestock means less predation and decreased HWC, but presents new issues. This study indicated that uptake of the HHP increases positive perceptions of snow leopard conservation and value of wildlife to local people. Results suggest that effective ecotourism 
schemes must address a combination of attitudes, norms, behavioral controls, and intentions of local people to address the intrinsic and instrumental values of wildlife beyond immediate economic benefits (Heath \& Heath, 2011).

The localized relationship between conservation and tourism also has implications for the snow leopard. For snow leopards to stand a chance of survival in an environment undergoing rapid change, tourism-based conservation interventions should consider both the needs of the local people as well as the global snow leopard survival strategy. This study supports continued use of existing socioeconomic monitoring protocols and success indicators of the Snow Leopard Survival Strategy current tourism guidelines (Snow Leopard Network, 2014), but some monitoring of social norms, perceived behavioral controls, and intentions should also be considered as part of this monitoring. Continued compliance with these guidelines when expanding the homestays program should support positive local perceptions of snow leopards, increasing the potential for success of future conservation interventions.

\section{References}

Agrawal, A., \& Redford, K. (2006). Poverty, development, and biodiversity conservation:

Shooting in the dark? Working Paper 26. Washington, DC: Wildlife Conservation Society. Ajzen, I. (1991). The theory of planned behavior. Organizational Behavior and Human Decision Processes, 50, 179-211.

Berkes, F. (2004). Rethinking community-based conservation. Conservation Biology, 18, 621-630.

Bhatia, S., Redpath, S. M., Suryawanshi, K., \& Mishra, C. (2017). The relationship between religion and attitudes toward large carnivores in northern India. Human Dimensions of Wildlife, 22, 30-42.

Bhatnagar, Y. V., Mathur, V. B., Sathyakumar, S., Ghoshal, A., Sharma, R. K., Bijoor, A., ... 
Lal, P. (2016). South Asia: India. In Snow leopards; Biodiversity of the world: Conservation from genes to landscapes (pp. 457-569). London, UK: Elsevier.

Chan, K. M. A., Balvanera, P., Benessaiah, K., Chapman, M., Díaz, S. ... Turner, N. (2016). Why protect nature? Rethinking values and the environment. PNAS, 113, 1462-1465.

Hampton, M. P. (2013). Backpacker tourism and economic development. Perspectives from the less developed world. London, UK: Routledge.

Heath, C., \& Heath, D. (2011). Switch: How to change things when change is hard. Waterville, ME: Thorndike Press.

Justus, J., Colyvan, M., Regan, H., \& Maguire, L. (2008). Buying into conservation: Intrinsic versus instrumental value. Trends in Ecology \& Evolution, 24, 187-191.

Khan, M. M. (1997). Tourism development and dependency theory: Mass tourism vs. ecotourism. Annals of Tourism Research, 24, 988-991.

Krüger, O. (2005). The role of ecotourism in conservation: Panacea or Pandora's box? Biodiversity and Conservation, 14, 579-600.

Liu, Z. (2003). Sustainable tourism development: A critique. Journal of Sustainable Tourism, 11, 459-475.

López-Guzmán, T., Sánchez-Cañizares, S., \& Pavon, V. (2011). Community-based tourism in developing countries: A case study. Tourismos, 6(1), 69-84.

Loram, C. (2004). Leh and trekking in Ladakh (3rd ed.). Surrey, UK: Trailblazer Publications. Namgail, T., Majumder, B., \& Dadul, J. (2016). Himalayan homestays: Fostering human-snow leopard coexistence. In Snow leopards; Biodiversity of the world: Conservation from genes to landscapes (pp. 164-68). London, UK: Elsevier.

Newing, H., Eagle, C. M., Puri, R. K., \& Watson, C. W. (2011). Conducting research in 
conservation: Social science methods and practice. London, UK: Routledge.

Rajashekariah, K., \& Chandan, P. (2013). Value chain mapping of tourism in Ladakh. New Delhi, India: World Wildlife Fund.

Salafsky, N., Cauley, H., Balachander, G., Cordes, B., Parks, J., Margoluis, C., ... Margoluis, R. (2001). A systematic test of an enterprise strategy for community-based biodiversity conservation. Conservation Biology, 15, 1585-1595.

SLC-IT (2017). Snow Leopard Conservancy - India Trust. Retrieved August 17, 2017, from http://snowleopardindia.org/why-choose-us.php

Snow Leopard Network (2014). Snow leopard survival strategy: Revised 2014 version. Seattle, WA: Snow Leopard Network.

Spiteri, A., \& Nepal, K. S. (2008). Evaluating local benefits from conservation in Nepal's Annapurna conservation area. Environmental Management, 42, 391-401.

Stem, C. J., Lassoie, J. P., Lee, D. R., Deshler, D. D., \& Schelhas, J. W. (2003). Community participation in ecotourism benefits: The link to conservation practices and perspectives. Society \& Natural Resources, 16, 387-413.

Vucetich, J. A., Bruskotter, J. T., \& Nelson, M. P. (2015). Evaluating whether nature's intrinsic value is an axiom of or anathema to conservation. Conservation Biology, 29, 321-332.

Waylen, K. A., Fischer, A., McGowan, P., Thurgood, S., \& Milner-Gulland, E. J. (2015). Effect of local cultural context on the success of community-based conservation interventions. Conservation Biology, 24, 1119-1129.

Wunder, S. (2000). Ecotourism and economic incentives: An empirical approach. Ecological Economics, 32, 465-479. 
Table 1. A summary of the themes, subthemes, topics of discussion, and quotes that emerged from the interviews.

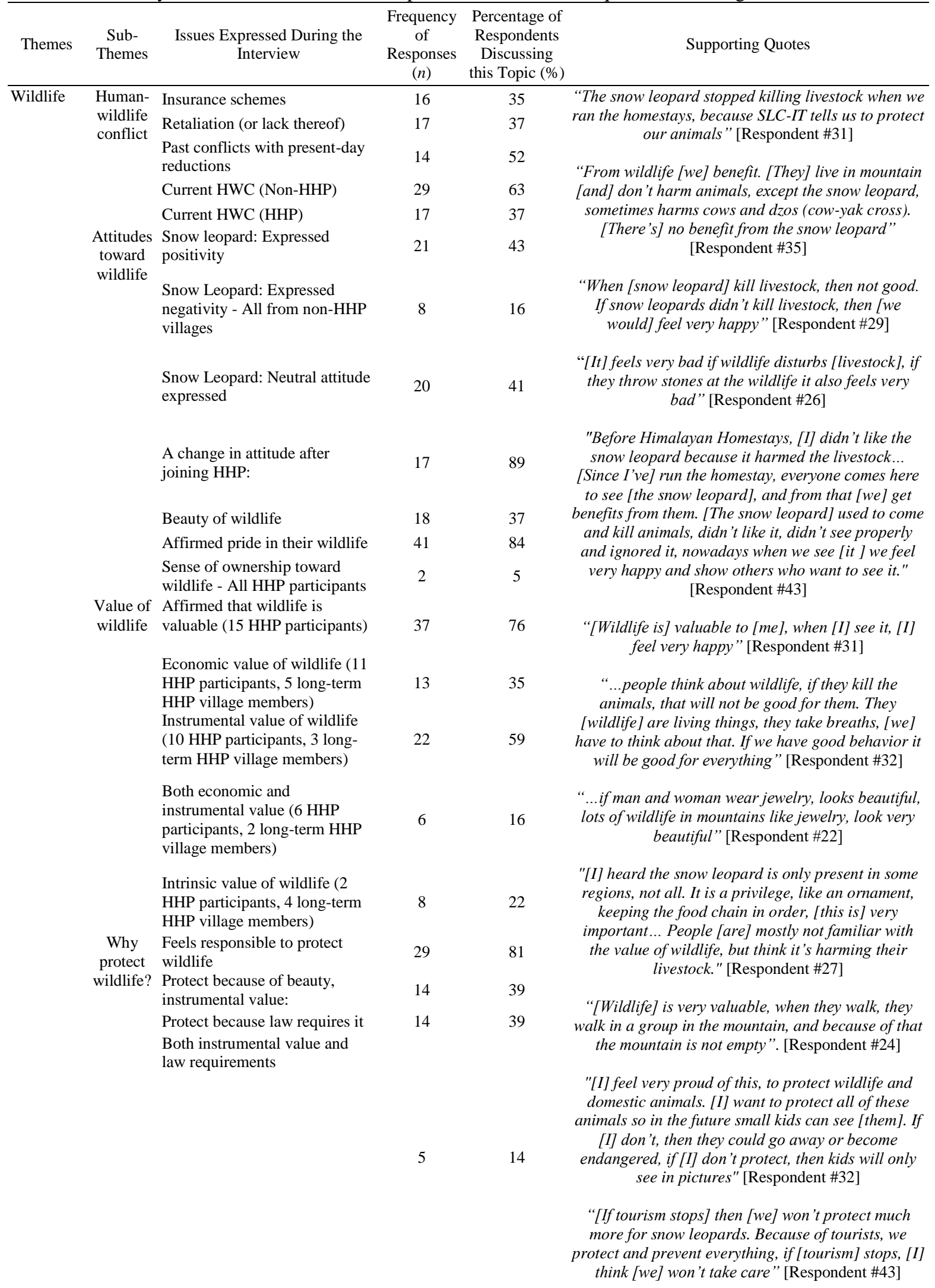


Protect because instructed

Protect wildlife because it attracts tourists

Tourism Benefits Benefits of tourism (18 were and HHP participants):

Issues

Economic benefits

Learning benefits

Both learning and economic benefits

Capacity building benefits

Tourism-associated issues

Distribution of economic

benefits issue discussed

Rotation system issues

discussed

Tourism Believed wildlife was the main Linkages attraction for tourists:

to Tourism was why they

wildlife protected wildlife (4 out of 5

were HHP participants)

Felt no responsibility for nature and wildlife in their area (HHP participants)

Felt no responsibility for nature and wildlife (non-HHP participants)

Conservation Awareness

Ecological Understanding
Indicated a change in attitude, mostly regarding involvement in the HHP and perception of wildlife.

Indicated behavioral changes, mainly concerning involvement in the HHP and HWC

mitigation

Felt they had no role in conservation.

Consider wildlife increasing

Consider wildlife decreasing

Pollution

Litter

Global warming

Acknowledged that snow leopards were threatened in the past from hunting, but hunting does not happen anymore.

Believed the snow leopard is not threatened by anything

"From [Wildlife department \& NGO], everyone comes here to tells [us] not to kill or harm wildlife. If [we] harm, [wildlife] will be getting less"

$$
\text { [Respondent \#34] }
$$

88

7

33

9

"If there was no tourism then wildlife would not be valuable" [Respondent \#41] "If there [are] homestays, that will benefit everyone"
[Respondent \#24, non-HHP participant]

"[I] used to not know anything about tourists, now with Himalayan Homestays, [I] interact with people and learn about culture and also have confidence with them in terms of questions and answers" [Respondent \#11]

"People who have Homestays benefit, otherwise nothing” [Respondent \#48]

"If there will be more tourists, this will be a benefit for [us]" [Respondent \#41]

"If everyone cooperates for the wildlife, the trekkers will come" [Respondent \#2]

"[We're] protecting to increase wildlife, if wildlife increases, more people will come to see" [Respondent \#49]

"Before Himalayan Homestays, [we] ignored the wildlife, but now the trekkers who come to see [wildlife] here feel happy, and [so] local people feel happy to see wildlife” [Respondent \#9, HHP participant]

"[When] snow leopard killed animals, [we used to] take the meat back to the village, now [we] leave for snow leopard to eat it all" [Respondent \#3]

"[Wildlife] will increase, no one is harming wildlife" [Respondent \#23]

“...some tourists care about the environment and teach us, don't throw trash” [Respondent \#46]

"Village is very clean, SLC-IT brought dustbins and sanitation" [Respondent \#6]

"50 years ago [it] was not hot, now very hot, [if this] increases, bad for everything” [Respondent \#2]

"No threats for snow leopard, he is the king of this valley" [Respondent \#22]

This was contradicted by one respondent with a formal education, who stated "[I] heard that wildlife is mostly hunted for parts, but [I] haven't seen that in this village" [Respondent \#27] 
Table 2. Recommended ecotourism interventions to affect positive behavior toward wildlife

Issue/focus of intervention

Attitude: Several non-intervention villages have expressed issues with Human Wildlife-Conflict (HWC).

Subjective Norm: Exclusive dependence on an inherently unstable tourism market may merely commodify wildlife, while leaving the livelihoods of the local people at risk.

Perceived Behavioral Control: Use HHP as a tool to build relationships within the village communities to build trust to support further interventions.

Intention: Intrinsic cultural value for wildlife expressed and reinforced in local narrative.
Method

Implement HHP in villages with $\mathrm{HWC}$ issues and potential for tourism success (e.g., villages with potential tourist traffic, adjacent trekking routes, infrastructure for homestays, local willingness to participate).

Implement effective ecotourism schemes in addition to other sources of income (e.g., agriculture, handicrafts, guiding, livestock).

New educational opportunities through training of (certified) nature guides and distribution of educational materials.

Involve communities in developing and embedding messages in training materials, tourist materials, and branding that support local cultural references to beauty of wildlife and the snow leopard as the 'jewelry of the mountains'. 


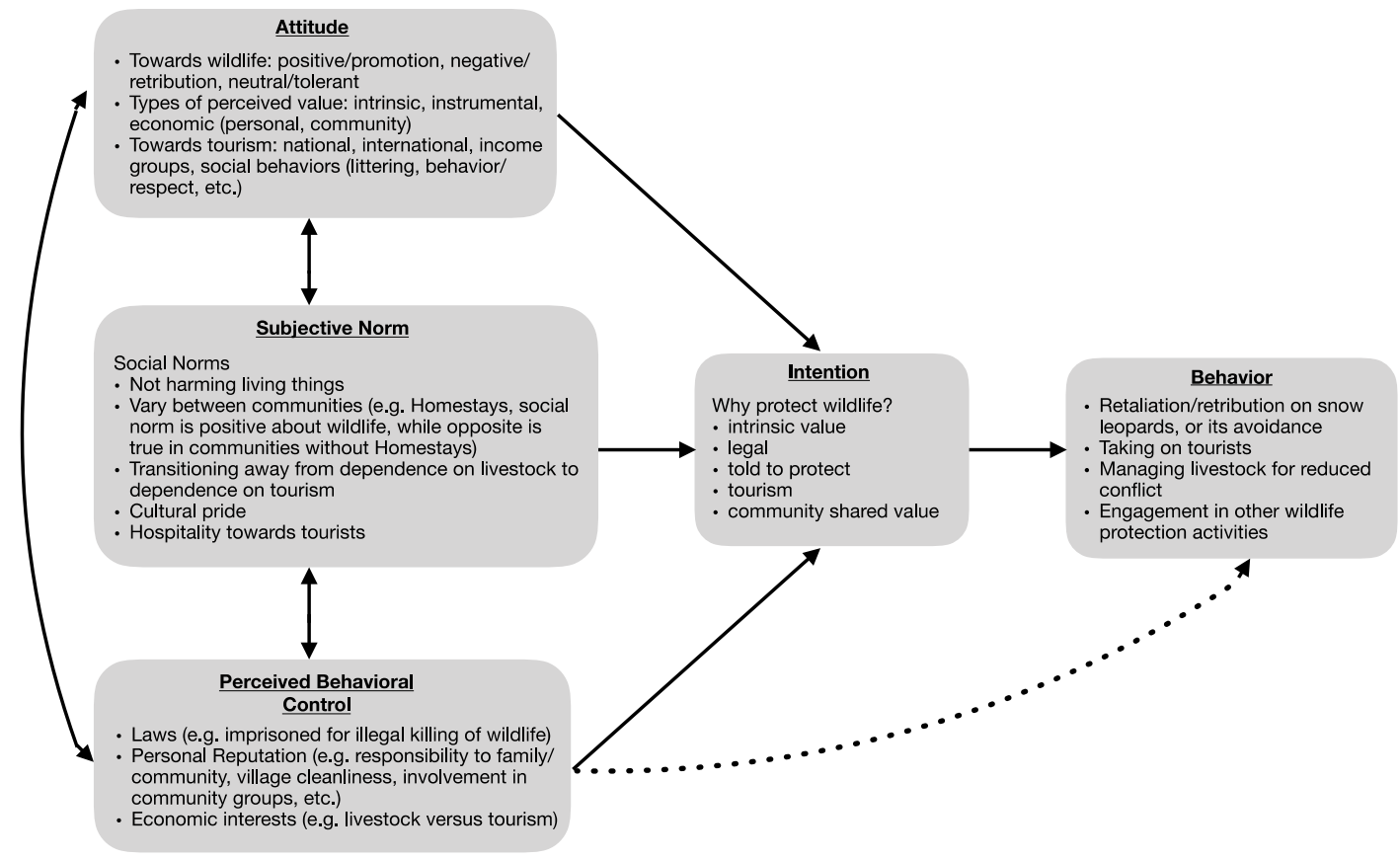

Figure 1. Schematic representation, derived from the Theory of Planned Behavior (Ajzen, 1991), linking people's expressed views with actual behavior including elements of local community identity, attitudes, and behavioral outcomes toward wildlife identified in this study in Ladakh. 